\title{
Development of Burkholderia mallei and pseudomallei vaccines
}

\section{Ediane B. Silva* and Steven W. Dow}

Department of Microbiology, Immunology, and Pathology, Regional Center of Excellence in Emerging Diseases and Bioterrorism, Colorado State University, Ft. Collins, CO, USA

Edited by:

Mark Estes, University of Georgia, USA

\section{Reviewed by:}

John Boyce, Monash University,

Australia

Joanna Goldberg, University of

Virginia Health System, USA

Dina Moustafa, University of

Virginia, USA

*Correspondence:

Ediane B. Silva, Department of Microbiology, Immunology, and Pathology, Colorado State University, 3185 Rampart Road, Campus Delivery 2025, Ft. Collins, CO 80523, USA.

e-mail:ediane.silva@colostate.edu
Burkholderia mallei and Burkholderia pseudomallei are Gram-negative bacteria that cause glanders and melioidosis, respectively. Inhalational infection with either organism can result in severe and rapidly fatal pneumonia. Inoculation by the oral and cutaneous routes can also produce infection. Chronic infection may develop after recovery from acute infection with both agents, and control of infection with antibiotics requires prolonged treatment. Symptoms for both meliodosis and glanders are non-specific, making diagnosis difficult. B. pseudomallei can be located in the environment, but in the host, B. mallei and $B$. psedomallei are intracellular organisms, and infection results in similar immune responses to both agents. Effective early innate immune responses are critical to controlling the early phase of the infection. Innate immune signaling molecules such as TLR, NOD, MyD88, and pro-inflammatory cytokines such as IFN- $\gamma$ and TNF- $\alpha$ play key roles in regulating control of infection. Neutrophils and monocytes are critical cells in the early infection for both microorganisms. Both monocytes and macrophages are necessary for limiting dissemination of B. pseudomallei. In contrast, the role of adaptive immune responses in controlling Burkholderia infection is less well understood. However, $T$ cell responses are critical for vaccine protection from Burkholderia infection. At present, effective vaccines for prevention of glanders or meliodosis have not been developed, although recently development of Burkholderia vaccines has received renewed attention. This review will summarize current and past approaches to develop $B$. mallei and B. pseudomalllei vaccines, with emphasis on immune mechanisms of protection and the challenges facing the field. At present, immunization with live attenuated bacteria provides the most effective and durable immunity, and it is important therefore to understand the immune correlates of protection induced by live attenuated vaccines. Subunit vaccines have typically provided less robust immunity, but are safer to administer to a wider variety of people, including immune compromised individuals because they do not reactivate or cause disease. The challenges facing B. mallei and B. pseudomallei vaccine development include identification of broadly protective antigens, design of efficient vaccine delivery and adjuvant systems, and a better understanding of the correlates of protection from both acute and chronic infection.

Keywords: Burkholderia, glanders, melioidosis, immune response, vaccine, live attenuated

\section{INTRODUCTION: DISEASES CAUSED BY B. mallei AND}

\section{B. pseudomallei INFECTION}

Glanders is the clinical disease caused by Burkholderia mallei infection. Horses, mules, and donkeys are highly susceptible to this bacterium and these infected animals serve as a natural reservoir, since the organism is not able to survive in the environment alone. Equine glanders transmission occurs though ingestion or direct contact with fomites. These zoonotic infections occur by contact with infected animals or following direct contact with B. mallei bacterial cultures (Dvorak and Spickler, 2008). The symptoms of glanders depend upon the route of infection and are often characterized by pneumonia, septicemia, and chronic suppurative infections of the skin (Srinivasan et al., 2001; Anuntagool and Sirisinha, 2002; Rosenbloom et al., 2002).
B. mallei infection spreads primarily hematogenously, and studies in hamster infection models have demonstrated lesions in the liver, spleen and lungs $6 \mathrm{~h}$ after intraperitoneal (i.p.) inoculation (Fritz et al., 1999). The host immune response to B. mallei depends critically on activation of innate immune responses (Goodyear et al., 2010, 2012b), whereas there is limited knowledge regarding adaptive immune responses during glanders infection.

Melioidosis is caused by infection with Burkholderia pseudomallei and the agent can cause infection in humans and animals (Cheng and Currie, 2005). The disease can develop following subcutaneous (s.c.) inoculation or ingestion or inhalation of the bacterium (Wiersinga and Van Der Poll, 2009). Certain environmental conditions can also increase the risk of contracting melioidosis. For example the rainy season may be associated with 
increased risk of septic and pneumonic forms of melioidosis (Currie and Jacups, 2003). As is the case with glanders, the route of $B$. pseudomallei infection also contributes to the severity of the disease (Barnes and Ketheesan, 2005).

B. pseudomallei infect a variety of cells, including mononuclear phagocytes and some non-phagocytic cells. Once inside macrophages, the organism can escape endocytic vesicles and live free within the cytoplasm (Jones et al., 1996). B. mallei and $B$ pseudomallei use BimA, a protein required for actin-based motility (Stevens et al., 2005b) and BimA homologuous proteins for cell-to-cell spread (Stevens et al., 2005a; Allwood et al., 2011) and the formation of multi-nucleate giant cells (Harley et al., 1998). In vivo, the bacterium can spread hematogenously to the liver, spleen or brain, and can also produce sepsis. However, the events underlying the spread of $B$. pseudomallei and the apparent predilection for sites such as the brain remain poorly understood (White, 2003; Owen et al., 2009). The olfactory sensory nerve is the main route to melioidosis brain infection (and to some degree the trigeminal nerve), though the authors could not explain the mechanism of travel of $B$. pseudomallei via the nerves (Owen et al., 2009).

The development of symptoms of melioidosis is dependent on several factors, including bacterial strain differences, variations in the host immune response, and the route of infection (Cheng and Currie, 2005). Acute infection is associated with severe pneumonia or rapid septicemias (Chaowagul et al., 1989). In the chronic stages of infection, meliodosis can lead to the formation of abscesses in multiple organs, or can lead to asymptomatic infection, which can apparently be reactivated after many years (Ngauy et al., 2005). Recent studies by our group suggest that the site of asymptomatic infection may actually be the gastrointestinal tract (Goodyear et al., 2012a).

Currently both B. pseudomallei and B. mallei are considered as potential bioweapons and they are classified by the Centers for Disease Control as category B select agents (Dance, 2002; Warawa and Woods, 2002). The use of B. mallei and B. pseudomallei as bioweapon stems primarily from the fact that clinical disease can develop following inhalational exposure to even very low infective doses of the organisms. In addition, B. pseudomalle $i$ is also endemic in the soil and water of certain regions of the world, adding to the ease with which bacterial strains can be isolated and propagated (Currie and Jacups, 2003; Peacock, 2006; Gilad et al., 2007; Ko et al., 2007). The B. pseudomallei organism can also be easily manipulated genetically (Mack and Titball, 1996). Effective treatment of melioidosis is limited by inherent bacterial resistance to several different classes of antibiotics and treatment of acute illness is typically associated with high morbidity and mortality rates (Warawa and Woods, 2002). For all the reasons noted above, development of effective $B$. mallei and $B$. pseudomalle $i$ vaccines are a priority in the emerging infectious disease field.

\section{HOST IMMUNE RESPONSE TO Burkholderia INFECTION}

Clinical and experimental studies indicate that Burkholderia infection rapidly activates the innate immune system. Depending on the dose and route of infection, the organism can be rapidly eliminated by this early innate immune response, primarily through the actions of monocytes and natural killer (NK) cells.
Macrophages play a critical role in the early phase of infection by controlling organism replication (Breitbach et al., 2006). However, if the initial infection is not controlled and chronic infection is established, $\mathrm{CD} 4^{+} \mathrm{T}$ cells become more important for long-term control of infection (Haque et al., 2006b). By determining what is required for a successful immune response against acute or chronic Burkholderia infection, it may also be possible to elucidate what is required for successful vaccine-induced protective immunity.

\section{INNATE IMMUNE RESPONSES TO Burkholderia INFECTION}

A fully functional innate immune system is critical to the efficient, early control of Burkholderia infection. The innate immune response to Burkholderia has been investigated in much greater detail than the adaptive immune response. Several key cell types are activated following Burkholderia infection, along with their cell surface signaling molecules, including Toll-like receptors (TLRs), NOD-like receptors (NLRs) and caspases. Key cytokines including MCP-1, INF- $\gamma$, and TNF- $\alpha$ also are required for protective immunity to Burkholderia infection.

\section{Role of TLR signaling in Burkholderia infection}

Cell surface expression of TLR1, TLR2, and TLR4 is upregulated on monocytes and neutrophils from patients infected with B. pseudomallei (Wiersinga et al., 2007a). Unlike the case with many Gram-negative pathogens, the lipopolysaccharide (LPS) from B. pseudomallei appears to activate macrophages only through TLR2 and not via TLR4 (Wiersinga et al., 2007b). Thus, in $B$. pseudomallei infection, TLR2 can be stimulated directly, whereas activation of TLR4 requires the coreceptors CD14 and MD2 (Hii et al., 2008). Mice lacking the TLR2 receptor are actually protected from $B$. pseudomallei infection, whereas TLR4 defective mice do not exhibit increased susceptibility to either B. mallei or B. pseudomallei infection (Wiersinga et al., 2007b; Goodyear et al., 2012b). Macrophage activation by B. pseudomallei results in production of pro-inflammatory cytokines, including TNF- $\alpha$, IL-1 $\beta$, and IL-6 (West et al., 2008). Host susceptibility to melioidosis is modulated by TLR polymorphisms, but the mechanisms of this effect are not well understood. For example: TLR4 polymorphisms are associated with increased risk of melioidosis and TLR6-1-10 region single nucleotide polymorphisms in diabetes patients are associated with differential susceptibility to melioidosis compared with other illnesses (West et al., 2012).

\section{NLRs and Burkholderia infection}

The NLRs NOD1 or NOD2 regulate IL-18 production following B. pseudomallei infection (Hii et al., 2008). Production of IL-18 in response to inflammasome signaling was shown to be protective against $B$. pseudomallei infection (Wiersinga et al., 2007c). Mice deficient in inflammasome components including ASC, caspase1, NLRC4, and NLRP3 were more susceptible to B. pseudomallei infection than wild type animals (Ceballos-Olvera et al., 2011).

\section{MyD88 signaling}

MyD88 signaling plays a key role in the protection against infection with both B. pseudomallei and B. mallei. For example, 
MyD88-/- mice infected with either B. pseudomallei or B. mallei were much more susceptible to infection than wild type mice (Wiersinga et al., 2008; Goodyear et al., 2012b). Interestingly, in MyD88-1- mice infected with B. pseudomallei, there was reduced early pulmonary neutrophil recruitment and a diminished activation of neutrophils compared to wild type mice (Wiersinga et al., 2008). The MyD88-dependent pathway may also contribute to a detrimental host inflammatory response (Ventura et al., 2009). MyD88 $8^{-/}$mice infected with $B$. mallei showed a decreased inflammatory response (Goodyear et al., 2012b). For example, numbers of monocytes, myeloid dendritic cells (DC) and neutrophils in the lungs of $B$. mallei infected MyD88 $8^{-/}$mice were reduced compared to wild type animals. The key defect in the MyD88 $8^{-/}$mice infected with B. mallei appeared to be a lack of IFN- $\gamma$ production, as IFN- $\gamma$ production was completely absent in MyD88 ${ }^{-/-}$animals and treatment of MyD88-/- animals with rIFN- $\gamma$ partially restored protective immunity (Goodyear et al., 2012b).

\section{Role of Caspase-1 in Burkholderia infection}

B. pseudomallei infection was shown to induce caspase-1 activation, causing macrophage cell death and triggering the release of IL-1 $\beta$ and IL-18 (Sun et al., 2005). The caspase-1 pathway was also shown to regulate IFN- $\gamma$ production following B. pseudomallei infection. Caspase- $1^{-/-}$mice were highly susceptible to B. pseudomallei infection with high bacterial loads and greatly diminished production of IFN- $\gamma$ (Breitbach et al., 2009).

\section{Role of MCP-1 in Burkholderia infection}

Monocyte chemoattractant protein-1 (MCP-1) was shown recently to play a critical role in protective immunity to $B$. mallei respiratory infection (Goodyear et al., 2010). Both MCP-1-/mice and mice lacking the $\mathrm{MCP}-1$ receptor $\left(\mathrm{CCR} 2^{-/-}\right.$mice) were more susceptible to $B$. mallei infection, with significantly higher bacterial burdens in lung, liver and spleen 3 days following intranasal challenge compared to wild type animals. Lack of monocyte and inflammatory DC recruitment to the lungs appeared to be the primary defect in $\mathrm{MCP}-1^{-/-}$animals, and in fact these animals actually had significantly greater numbers of neutrophils in the lungs. In addition, IFN- $\gamma$ concentrations were markedly decreased in infected $\mathrm{MCP}-1^{-/}$and CCR2 $2^{-/-}$ mice. Treatment with exogenous rIFN- $\gamma$ helped restore effective immunity and increased survival significantly (Goodyear et al., 2010).

\section{Role of TNF- $\alpha$}

TNF- $\alpha$ is required to control the infection caused by B. pseudomallei in mouse models. For example, TNF- $\alpha^{-/-}$mice were much more susceptible to $B$. pseudomallei infection, with increased bacterial loads in spleen and liver and high mortality rates of TNF- $\alpha^{-/-}$, TNFR1, and TNFR2 $2^{-/-}$animals (Barnes et al., 2008). However, in human melioidosis patients with sepsis, increased TNF- $\alpha$ production is thought to actually be associated with higher mortality rates (Suputtamongkol et al., 1992). While $\mathrm{BALB} / \mathrm{C}$ and $\mathrm{C} 57 \mathrm{Bl} / 6$ mice both readily develop chronic infection, BALB/c mice are more susceptible to acute infection (Liu et al., 2002). There are some notable differences in the immune response to $B$. pseudomallei between mouse strains. For example, TNF- $\alpha$ concentrations were markedly higher in the livers of $\mathrm{BALB} / \mathrm{c}$ mice following lethal $B$. pseudomallei infection, whereas concentrations were lower in the livers of $\mathrm{C} 57 \mathrm{Bl} / 6$ mice (Ulett et al., 2000). Thus, TNF- $\alpha$ appears to play a dual role in regulation of both protection and susceptibility to Burkholderia infection. It would therefore be difficult to predict whether vaccine induction of TNF- $\alpha$ production would be a desirable biological endpoint.

\section{Role of IFN- $\gamma$}

Unlike TNF- $\alpha$, the role of IFN- $\gamma$ in protection from Burkholderia infection is unambiguous and IFN- $\gamma$ is obviously a key protective cytokine. For example, IFN $-\gamma^{-/-}$mice are highly susceptible to infection with both B. mallei and B. pseudomallei (Santanirand et al., 1999; Haque et al., 2006b; Koo and Gan, 2006; Rowland et al., 2006; Easton et al., 2007; Goodyear et al., 2009, 2010). In addition, mice depleted of IFN- $\gamma$ with antibodies are also very susceptible to infection (Santanirand et al., 1999; Breitbach et al., 2006; Haque et al., 2006b; Whitlock et al., 2008; Wiersinga et al., 2008). IFN- $\gamma$ production regulates intracellular killing of Burkholderia and organ burdens are uniformly higher in IFN$\gamma^{-/-}$mice compared to wild type animals infected with B. pseudomallei. The source of IFN- $\gamma$ production in vivo has not been fully elucidated, but our studies have shown high levels of IFN$\gamma$ production by NK cells in the lungs (Goodyear et al., 2009). In vitro studies have shown that $B$. pseudomallei infection elicits IFN- $\gamma$ production from NK cells, NKT cells, and conventional $\mathrm{T}$ cells in an IL-12 and IL-18-dependent manner (Haque et al., 2006b).

\section{Role of IL-12}

The presence of both subunits of IL-12 (IL-12p40 and IL-12p35) was shown to be critical for IFN- $\gamma$ production in vitro in response to heat-killed B. mallei (Rowland et al., 2006). In addition, neutralization of IL-12 in vivo resulted in increased susceptibility of mice to lethal infection (Santanirand et al., 1999). The role of IL-12 may be primarily to drive NK cells and T cells to IFN- $\gamma$ production.

\section{INNATE CELLULAR IMMUNITY TO Burkholderia INFECTION Role of macrophages}

Macrophages play a critical role in early stages of $B$. pseudomallei infection, as deduced from studies in C57BL/6 and $\mathrm{BALB} / \mathrm{c}$ mice (Breitbach et al., 2006). Macrophage killing of Burkholderia is dependent on the presence of IFN- $\gamma$ derived from NK cells, CD8 ${ }^{+}$, and TCR- $\gamma \delta$ T cells (Rowland et al., 2006). Though controversial, there is also evidence that iNOS is also required for macrophage control of $B$. pseudomallei infection, though in vitro and in vivo experiments give conflicting results in this regard (Utaisincharoen et al., 2004; Breitbach et al., 2006, 2011). Macrophage dysfunction in diabetes mellitus is thought to explain in part the extreme susceptibility of diabetics to lethal meliodosis infection (Hodgson et al., 2011).

\section{Role of monocytes}

Recent studies performed in our laboratory indicate that monocytes play a critical role in the early control of $B$. mallei infection 
(Goodyear et al., 2010). For example, mice in which monocyte migration is impaired (CCR $2^{-/-}$mice) are extremely susceptible to inhaled and parenteral challenge with $B$. mallei. This increased susceptibility is associated with significant impairment in monocyte and DC entry into the lungs following inhalational challenge with $B$. mallei. In these mice, production of IL-12 by inflammatory DC is also significantly impaired following $B$. mallei challenge. In another study, depletion of monocytes using a depleting antibody to Gr-1 also increased susceptibility to B. pseudomallei infection (Rowland et al., 2010).

\section{Role of neutrophils}

Gr- $1^{+}$neutrophils are also essential to early control of B. mallei infection, based on the results of antibody depletion studies (Rowland et al., 2010). Neutrophil depletion with a cross-reactive Gr-1 antibody severely exacerbated disease, resulting in an acute lethal infection associated with a 1000-fold increase in lung bacterial loads within 4 days. Neutrophils also play an important indirect role in the generation of the early cytokine environment in the lungs (Easton et al., 2007). Neutrophil dysfunction may also help explain the increased susceptibility of diabetics to meliodosis, as polymorphonuclear (PMN) cell responses to B. pseudomallei were impaired due to defects in migration and apoptosis (Chanchamroen et al., 2009).

\section{Role of natural killer cells}

NK cells are estimated to produce up to $80 \%$ of IFN- $\gamma$ in the early stages of B. pseudomallei infection and IFN- $\gamma$ is a key cytokine for control of B. pseudomallei infection (Haque et al., 2006b). NK cells are also the major source of IFN- $\gamma$ production in early B. mallei infection (Rowland et al., 2006; Goodyear et al., 2012b). Thus, NK cells may help control Burkholderia infection indirectly by activating macrophages via IFN- $\gamma$ to kill intracellular Burkholderia.

\section{ADAPTIVE IMMUNE RESPONSE TO Burkholderia}

While the role of innate immunity in controlling both $B$. mallei and B. pseudomallei infections has been investigated in relative detail, much less is known about the role of adaptive immune responses ( $\mathrm{T}$ cell and B cell responses) in controlling Burkholderia infection.

\section{Role of T cells}

Protection against B. pseudomallei infection appears to depend on both strong humoral and cell-mediated immunity (Healey et al., 2005). For example, $\mathrm{CD}^{+}{ }^{+} \mathrm{T}$ cells were shown in mouse infection models to play an important role in resistance to $B$. pseudomallei infection during the later stages of the acute infection (Haque et al., 2006b). In contrast, the same authors found that $\mathrm{CD}^{+} \mathrm{T}$ cells were much less important in resistance to melioidosis (Haque et al., 2006b). However, in general very little is known regarding the role of specific $\mathrm{T}$ cells subsets in regulating the tempo or the course of Burkholderia infection.

\section{Role of $B$ cells and antibodies}

IgM antibodies were detected only in patients with localized B. pseudomallei infection. On the other hand, IgG antibodies were detected in patients during the acute infection. IgG1 and IgG2 antibodies were observed in all patient groups while an IgG3 response was seen only in survivors of septicaemic infection, suggesting that these antibody isotypes may be a good indicator of active disease (Ho et al., 1997) or a good monitor of therapy (Vasu et al., 2003). The level of IgA, IgG, and IgM titers increase during an active infection with glanders, but the titers decreased within 14 months after infection (Waag et al., 2012).

Serum from meliododis patients contains antibodies that target LPS (Bryan et al., 1994; Ho et al., 1997; Charuchaimontri et al., 1999; Chenthamarakshan et al., 2001). A monoclonal antibody (Mab Ps6F6) specific to B. pseudomallei exopolysaccharide offered significant protection in a murine sub-acute meliodosis model. The Mab Ps6F6 provided a moderate and transient reduction of inflammatory responses in infected mice but was only partially protection because this antibody was not able to provide sterilizing protective immunity (Bottex et al., 2005). Antibodies to Burkholderia Hep_Hag autotransporter (BuHA) proteins were present in horses with glanders and in human patients with melioidosis (Tiyawisutsri et al., 2007).

There is also evidence for an important protective role for B cells and antibodies in Burkholderia infection. For example, depletion of $B$ cells significantly decreased survival time of B. mallei-infected BALB/c mice compared to non-depleted controls (Whitlock et al., 2008). It was speculated that antibody opsonization increased intracellular killing of $B$. mallei by increasing uptake by macrophages, but this was not formally demonstrated. Other studies have proposed that antibodies increase phagocytosis of Burkholderia (Bryan et al., 1994). Conversely, however, in a separate study when $\mu \mathrm{MT}$ mice (which lack all B cells) were infected with $B$. mallei, the $\mathrm{B}$ cell deficient animals were not found to be more susceptible to infection than wild type mice (Rowland et al., 2010). It is difficult to fully reconcile these very different results at present, but the discordant results could be a consequence of how B cells were depleted, of unanticipated effects of B cell depletion versus genetic deletion of B cells, or in the particular challenge models that were used in the studies.

\section{TARGETS FOR VACCINATION AGAINST Burkholderia}

Currently, prolonged antibiotic therapy and early diagnosis are the only options for controlling infections with either $B$. mallei or B. pseudomallei. While B. mallei remain uncommon and largely controlled in the equine population, except in some Asian and African countries, B. pseudomallei is much more widely distributed worldwide (Blancou, 1994; Currie et al., 2008). In fact, recent studies point to an expanded range of B. pseudomallei endemic countries, including Brazil, Central America, and regions of Asia and India.

While these data do not necessarily suggest that B. pseudomallei is spreading, they do point out that a much greater population of civilians has some risk of contracting B. pseudomallei infection from their environment. However, the incidence of meliodosis does not currently justify vaccination, except in certain regions such as Thailand and northern Australia where the disease incidence is high enough to warrant consideration of a prophylactic vaccine. However, there are currently no approved vaccines for either meliodosis or glanders prevention in humans or animals. 
Thus, it is believed that efforts to develop a new Burkholderia vaccine can be readily justified. In the last portion of this review, we will discuss the various approaches that have been taken to produce effective Burkholderia vaccines. One substantial hurdle that must be overcome by Burkholderia vaccines is to protect from both acute infection and chronic infection. The latter is a much more difficult hurdle and few vaccines have demonstrated a convincing ability to fully protect from the development of the chronic infection phase of B. pseudomallei infection. Efforts to produce a Burkholderia vaccine can be broadly classified as subunit vaccines, live attenuated vaccines, and killed bacteria vaccines delivered with or without adjuvants. Table 1 summarizes several attempts to provide vaccine-mediated protection against glanders and melioidosis.

\section{BACTERIAL VIRULENCE FACTORS AS POTENTIAL IMMUNE TARGETS FOR VACCINATION}

The ability to target bacterial virulence factors with vaccines has the potential to greatly attenuate the pathogenicity of Burkholderia and thereby suppress replication, allowing the host immune system to eradicate the organism before infection is wellestablished. A number of Burkholderia virulence factors have been identified and several have been evaluated as vaccine candidates.

\section{Type III and VI secretion systems}

B. pseudomallei type III secretion systems (T3SS) plays a role in early vacuolar escape, cell to cell spread in macrophages, and virulence (Stevens et al., 2002; Warawa and Woods, 2005; Burtnick et al., 2008). One component of the T3SS (BipD) has been tested as a candidate vaccine. Mice vaccinated by the i.p. route had a slightly prolonged early survival and reduced bacterial burden, but in general survival times were not prolonged compared to non-vaccinated mice subjected to the same B. pseudomallei challenge (Stevens et al., 2004). Other proteins from the T3SS system (BipB, BipC, or BipD) have also been evaluated as candidate vaccines, however, none of these three antigens generated protective immunity in challenge studies (Druar et al., 2008). In studies in our laboratory, we noted that intranasal vacctination of mice with BimA and two other Burkholderia antigens, induced protective immunity against an inhaled challenge (Whitlock et al., 2010).

The type VI secretion system (T6SS) is an important virulence factor that is necessary for the intracellular lifestyle of B. pseudomallei. Studies have shown that the T6SS Hcp1 protein from B. pseudomallei and B. mallei was recognized by convalescent serum from humans with documented meliodosis (Schell et al., 2007). Moreover, the T6SS proteins Hcp1, Hcp2, Hcp3, Hcp4, Hcp5, and Hcp6 have all been evaluated individually as candidate B. pseudomallei vaccines, but each has failed to provide complete protection in murine challenge models evaluated to date (Burtnick et al., 2011). However, it remains conceivable that a multi-valent T6SS vaccine could generate more effective immunity.

\section{Quorum sensing molecules}

Quorum sensing is important to the pathogencity of Burkholderia. In this process, molecules secreted by bacteria growing under conditions of crowding or stress help to regulate metabolism and survival functions of bacteria. LuxL and LuxR [N-acyl-homoserine lactone (AHL) receptors] are the most common signaling molecules found in gram negative bacteria and are also the major quorum sensing molecules involved in the virulence process of Burkholderia (Whitehead et al., 2001; Eberl, 2006). A B. pseudomallei LuxL mutant was significantly attenuated for infection in mice (Ulrich et al., 2004). The ability of several different $B$. mallei LuxI mutants to function as attenuated vaccines was also evaluated, using bmaII, bmaI3, and bmaR5 mutants, followed by challenge with fully virulent B. mallei. Only mice vaccinated with the bmaI3 mutant showed any level of protection, with survival of 3 of the 10 animals, 11 days after challenge (Ulrich et al., 2004).

\section{Surface expressed molecules as vaccine targets}

LPS and capsular polysaccharide (CPS) are the main surfaceassociated antigens of B. mallei and B. pseudomallei (Perry et al., 1995; Deshazer et al., 1998; Reckseidler et al., 2001; Atkins et al., 2002a; Sarkar-Tyson et al., 2007; Tuanyok et al., 2012). B. pseudomallei CPS is essential to bacterial virulence and this antigen activates the Th1 immune response (Warawa et al., 2009). Immunization against either antigen has been shown to provide partial protection against intranasal challenge with virulent B. pseudomallei (Trevino et al., 2006; Aucoin et al., 2012). The combination of both antigens provided better protection, even when administered in lower doses (Charuchaimontri et al., 1999; Jones et al., 2002; Nelson et al., 2004; Zhang et al., 2011). However, the antigen combination did not provide sterilizing immunity but did significantly decrease the bacterial burden in the spleen (Aucoin et al., 2012). In another study, vaccination with a mutant type II O-antigenic polysaccharide (O-PS) molecule also provided partial protection from infection with $B$. pseudomallei infection (Deshazer et al., 1998).

The efficacy of LPS or CPS as vaccines was tested in BALB/c mice (Nelson et al., 2004; Ngugi et al., 2010). Strong IgM and IgG3 responses were observed in mice vaccinated with LPS, whereas higher IgG2b responses were noted in mice immunized with CPS. After challenge with virulent B. pseudomallei by the i.p. route, there was partial protection in mice vaccinated with LPS, with $50 \%$ survival by day 35 . Partial protection was also observed in the group vaccinated with CPS. However, when mice were challenged by the pulmonary route, there was no protection (Nelson et al., 2004). Thus, it appears that both LPS and CPS are important candidate vaccine antigens. Both antigens appear to provide at least partial protection from challenge with Burkholderia by parenteral routes, whereas neither has been particularly effective for protection from challenge by the inhalational route. In addition, neither LPS nor CPS vaccines protect from the development of chronic infection.

The ability of anti-LPS and anti-CPS monoclonal antibodies to provide passive protection from challenge with Burkholderia has also been evaluated. When mice were administered mAbs against LPS or CPS, there was protection against i.p. challenge with $10^{4}$ CFU of a virulent strain of B. pseudomallei (NCTC 4845) (Jones et al., 2002). However, at higher challenge doses, only a mixture of both mAbs was able to provide significant protection. In addition, the mAbs did not provide protection from aerosol challenge 


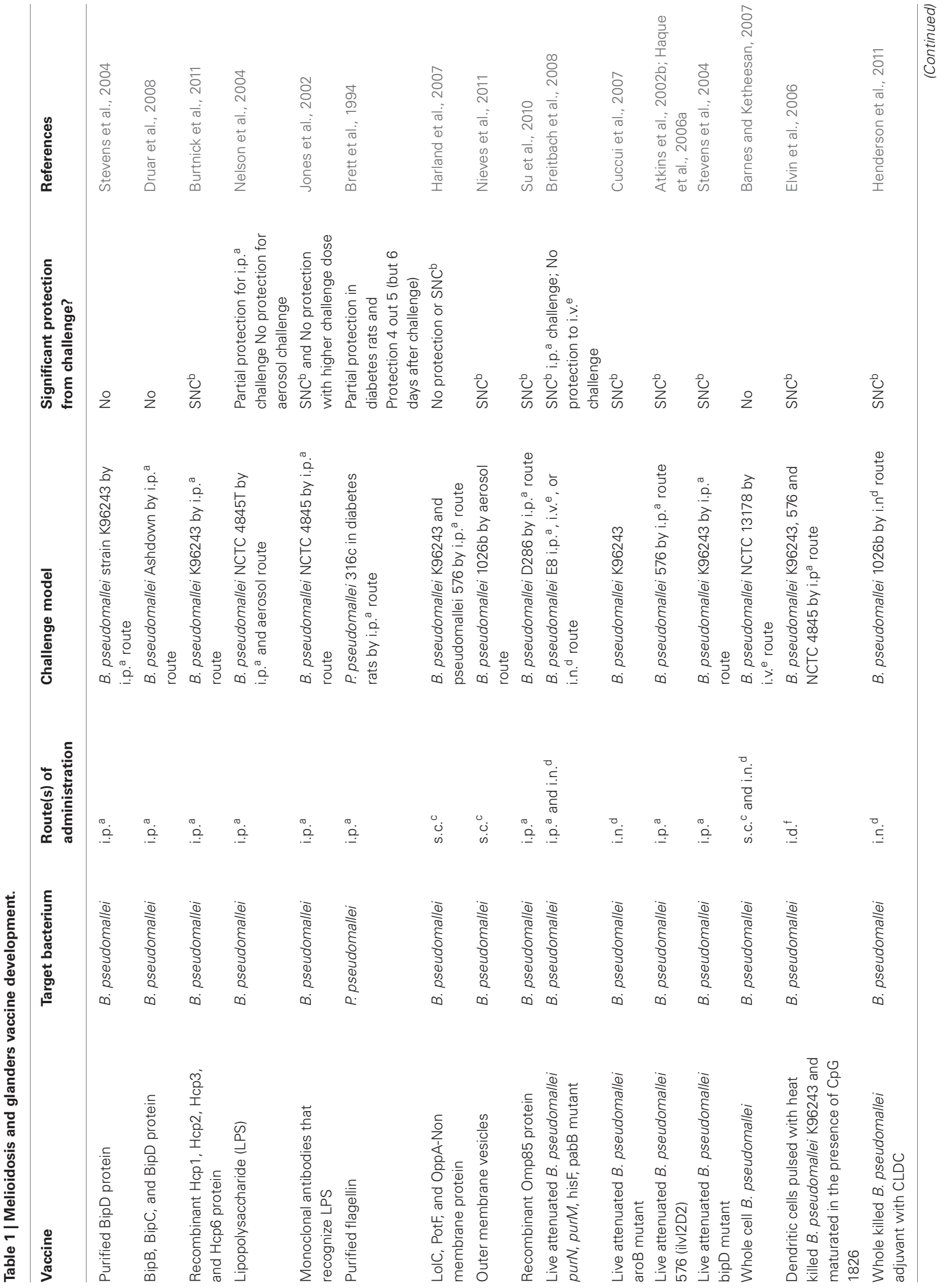




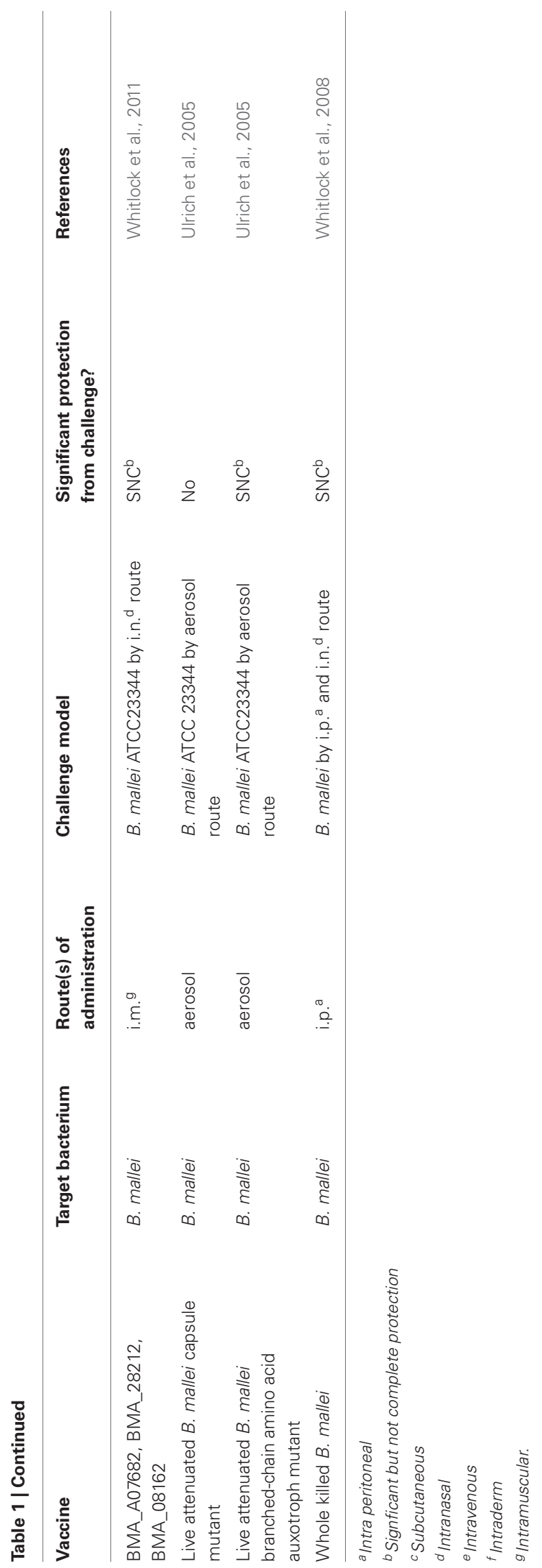

with B. pseudomallei (Nelson et al., 2004). Infusion of an anti-LPS antibody also protected mice from glanders when administered immediately prior to lethal challenge with B. mallei (Trevino et al., 2006).

\section{Flagellin}

Flagellin is an important molecule required for motility by B. pseudomallei (B. mallei does not have a flagellin molecule) (Deshazer et al., 1997; Wajanarogana et al., 1999; Chua et al., 2003; Nierman et al., 2004). In one study BALB/c mice were vaccinated with plasmid DNA encoding the flagellin gene fliC. Following intravenous challenge, $83 \%$ of the vaccinated mice survived for 7 days. Besides the increased survival rate, the vaccinated mice had a higher level of flagellin-specific antibodies and a higher level of IFN- $\gamma$ production by splenocytes. It was suggested that the mechanism of protection was provided by the Th1 immune response due to the increased production of IFN $-\gamma$ and the higher ratio of the IgG2a/IgG1 antibody response (Chen et al., 2006). Administration of a $\mathrm{mAb}$ directed against flagellin also provided partial protection (55\%) to diabetic rats challenged by the i.p. route with B. pseudomallei (Brett et al., 1994). It was speculated that anti-flagellin antibodies may immobilize Burkholderia and thereby attenuate pathogenicity (Brett et al., 1994; Deshazer et al., 1997).

\section{Outer membrane proteins}

An outer membrane protein was evaluated as a meloidosis vaccine (Hara et al., 2009; Su et al., 2010). Immunization in BALB/c mice with outer membrane protein 85 (Omp85) using Freund's complete adjuvant, promoted a strong antibody responses and provided significant protection against B. pseudomallei D286 challenge with $70 \%$ of survival at 15 days post infection. However, sterilizing immunity was not achieved, as vaccinated mice developed chronic infection (Su et al., 2010).

\section{Burkholderia pseudomallei PROTEIN SUBUNIT VACCINES}

Several different immunogenic proteins of Burkholderia have been identified as potential candidate vaccine antigens. Protein subunit vaccines are appealing because vaccine production is simplified and with newer adjuvants many proteins can be rendered highly immunogenic.

\section{Non-membrane proteins}

Three different $B$. pseudomallei proteins from ATP-binding cassette $(\mathrm{ABC})$ transport systems have been evaluated as potential vaccine candidates. One is LolC, which is an $\mathrm{ABC}$ transporter protein, first identified as an immunogen (Yakushi et al., 2000; Harland et al., 2007). The second antigen is PotF, which is a periplasmic binding protein of the PotFGHI system (Shah and Swiatlo, 2006) and is a homolog of the Agrobacterium tumefaciens PotF which is required for attachment and virulence (Matthysse et al., 1996). A third antigen (OppA), which is an oligopeptidebinding protein of the Opp system in E. coli (Detmers et al., 2001), has also been identified as a potential immunogen (Tanabe et al., 2006; Harland et al., 2007). Immunization with each of these proteins has been shown to stimulate antigen-specific humoral and cellular immune responses (Harland et al., 2007). Immunization with recombinant LolC or PotF proteins generated significant 
protection against $B$. pseudomallei challenge by the i.p. route and provided greater than $50 \%$ protection (Harland et al., 2007). In contrast, immunization with recombinant OppA protein did not generate significant protection. Since the LolC is also present in B. mallei, the authors speculated that LolC protein may also protect against glanders but this was not tested in the study (Harland et al., 2007).

In another study, immunogenic antigens were identified from a genomic screen of $B$. mallei expressed proteins. Three of these antigens, including LolC, were found to provide partial protection against $B$. malle $i$ and $B$. pseudomalle $i$ following intranasal vaccination (Whitlock et al., 2010, 2011). Notably, the LolC antigen was shown to provide cross-protection against both B. pseudomallei and $B$. mallei in this intranasal vaccination model (Whitlock et al., 2010, 2011). Thus, it appears that protein subunit vaccines targeting highly immunogenic Burkholderia proteins have the potential to be used as effective vaccines. However, it is likely that polyvalent vaccines combining several antigens may be more effective than single antigen vaccines.

\section{Burkholderia LIVE ATTENUATED VACCINES}

A number of different live attenuated Burkholderia vaccines have been developed and evaluated in mouse challenge models. In general, live attenuated vaccines have been found to provide superior protective immunity when compared to other potential Burkholderia vaccines. However, the use of live attenuated vaccines by parenteral routes of immunization is associated with more safety and production issues compared with subunit vaccines.

\section{B. pseudomallei live attenuated vaccines}

Several different attenuated strains of Burkholderia have been evaluated as potential live vaccine strains for protection from B. pseudomallei. A number of different attenuation strategies have been investigated to produce these candidate vaccines.

The most extensively investigated live attenuated vaccine to date has been the 2D2, which is an auxotroph for branched chain amino acids. It is a mutant strain of B. pseudomallei, which was produced by mutating the ilvI gene encoding the large subunit of the acetolactate synthase enzyme (Atkins et al., 2002b). The 2D2 strain of B. pseudomallei was also shown not to persist in vivo following immunization (Atkins et al., 2002b). When BALB/c mice were vaccinated with $2 \mathrm{D} 2$ by the i.p route, there was significant but incomplete protection against i.p. challenge of fully virulent wild type $B$. pseudomallei. The incomplete protection was melioidosis specific since protection against Francisella tularensis, was not observed (Atkins et al., 2002b). The immune mechanism of protection appeared to require primarily $\mathrm{CD} 4^{+} \mathrm{T}$ cells, as $\mathrm{CD} 4^{+} \mathrm{T}$ cell depletion eliminated the protective effects of $2 \mathrm{D} 2$ vaccination (Haque et al., 2006a).

In another attenuated vaccine approach, a B. pseudomallei capsular mutant (B. pseudomallei 1E10) was evaluated as a vaccine candidate. Immunization with the capsular mutant $1 \mathrm{E} 10$ by the i.p. route resulted in no protection against virulent challenge (Atkins et al., 2002a).

Transposon mutants of $B$. pseudomallei have also been evaluated as candidate vaccines. Mutants in several key Burkholderia biosynthetic pathways ( $p u r N$, purM, hisF, and $p a b B$ ) have been investigated for protective immunogenicity (Pilatz et al., 2006; Breitbach et al., 2008). All of the mutant strains conferred some degree of protection against virulent challenge in susceptible $\mathrm{BALB} / \mathrm{c}$ mice. Mice immunized by the intranasal and i.p. routes with the purN mutant were protected from acute infection following intranasal challenge (Breitbach et al., 2008). However, vaccinated mice were not protected from the development of chronic infection. The immunogenicity of a purM mutant strain of B. pseudomallei was also evaluated, but was found to provide only partial protection from virulent challenge, and immunization by either the intranasal or i.p. routes did not appear to affect protective efficacy (Breitbach et al., 2008). It was speculated that the greater apparent immunogenicity of the purN mutant bacterium was due to greater persistence of this strain following vaccination than the purM strain.

It should also be noted that a purM mutant strain (Bp82) of B. pseudomallei was recently approved by the CDC for use as an approved BSL2 level organism (Propst et al., 2010). This attenuated strain of $B$. pseudomalle $i$ was shown to be extremely safe even in very immune compromised animals.

aroB auxotrophic mutant strain $13 \mathrm{~B} 11$ has also been evaluated as a candidate live attenuated vaccine (Cuccui et al., 2007). The $13 \mathrm{~B} 11$ aroB mutant strain did not cause disease in mice when inoculated at either $1 \times 10^{5}$ or $1 \times 10^{6} \mathrm{CFU}$ by the intranasal route. Furthermore, the aro $B$ mutant was cleared from the lungs and spleen of mice within 3 days. Vaccinated mice showed an increased time to death when challenged with virulent $B$. pseudomallei but in the end all mice succumbed to the infection (Cuccui et al., 2007). An aroC deletion mutant of B. pseudomallei (A2) was also tested as a vaccine candidate (Foulongne et al., 2001; Srilunchang et al., 2009). Immunization with A2 by the i.p. route provided significant protection against virulent challenge in C57Bl/6 mice, but not in BALB/c mice (Srilunchang et al., 2009).

A T3SS apparatus mutant (B. pseudomallei bipD), has also been evaluated for protective immunity (Stevens et al., 2004; Druar et al., 2008). Mice inoculated with the B. pseudomallei bipD mutant strain were partially protected against subsequent challenge by the i.p. route with wild-type $B$. pseudomallei. In contrast, immunization of mice with recombinant BipD protein was not protective (Stevens et al., 2004; Druar et al., 2008).

\section{B. mallei live attenuated vaccines}

B. mallei capsule mutants and auxotrophs have been evaluated as glanders vaccines. Mice immunized by the aerosol route with a capsule mutant (DD3008) of B. mallei strain ATCC23344 developed high antibody responses (Ulrich et al., 2005). However, mice were not protected against aerosol challenge with a high dose of virulent $B$. mallei, presumably in part because the lack of mucosal IgA or IgG antibody responses (Ulrich et al., 2005). Immunization with an auxotrophic mutant of B. mallei (ILV1) elicited a Th1-like IgG subclass (IgG2a) antibody response, and provided significant short-term survival to challenge by the aerosol route with virulent $B$. mallei. In addition, immunization also provided significant protection to challenge by the aerosol route. It should be noted, however, that all mice surviving acute challenge developed chronic infection. It was speculated 
that the axotrophic mutants were more effective immunogens than capsule mutants (Amemiya, 2002; Ulrich et al., 2005). An attenuated $\operatorname{ctp} A$ mutant of $B$. mallei was also evaluated as a live attenuated vaccine, and found to provide partial protection against i.p. inoculation with virulent B. mallei (Bandara et al., 2008).

\section{INACTIVATED WHOLE CELL Burkholderia VACCINES}

Immunization with killed whole bacteria (bacterin vaccines) has been shown previously to provide effective immunization against a variety of bacterial diseases. These vaccines are relatively simple to produce and are safer than live attenuated vaccines and provide relatively high levels of specific immunity. However, vaccine site reactions are a potential problem with this class of vaccines.

\section{Burkholderia pseudomallei killed vaccines}

Live B. pseudomallei NCTC 13179, killed bacterial cells alone, or culture filtrate antigens (CFA) or lysates from B. pseudomallei cultures were tested as candidate vaccines following administration by the s.c. or i.v. routes, in BALB/c and C57BL/6 mouse i.v. challenge models. The live vaccine as well as lysates from B. pseudomallei and killed bacterial cells mixed with complete Freund's adjuvant all induced protective immunity. However, only the live vaccine stimulated a Th1 immune response (Barnes and Ketheesan, 2007).

In another study, the ability of vaccine adjuvants to enhance the immunogenicity of killed Burkholderia vaccines was evaluated. Mice were immunized intranasally with heat-killed B. pseudomallei, with or without a liposomal adjuvant (CLDC) and protective immunity to intranasal challenge assessed (Henderson et al., 2011). Immunization with CLDC adjuvant plus heat killed bacteria gave superior immunity compared to immunization with heat-killed bacteria alone.

The relative ability of heat-killed vaccines prepared with Burkholderia thailandensis, B. mallei, or B. pseudomallei cells was compared for induction of protection against melioidosis and glanders (Whitlock et al., 2008; Sarkar-Tyson et al., 2009; Henderson et al., 2011). Both the B. mallei and B. pseudomallei vaccines provided significant protection against $B$. pseudomalle $i$ challenge, whereas the $B$. thailandensis vaccine failed to elicit protective immunity. The probable mechanism of protection may have involved induction of antibody responses to the CPS and LPS and was $\mathrm{CD}^{+}{ }^{+} \mathrm{T}$ cell dependent (Sarkar-Tyson et al., 2009).

\section{Burkholderia mallei killed vaccines}

Immunization with heat-killed $B$. malle $i$ vaccines was evaluated for evidence of protection in mouse challenge models. Mice immunized i.p. with a heat-killed $B$. mallei vaccine were significantly protected from i.p. challenge with $B$. mallei (Whitlock et al., 2008). Antibody depletion studies indicated that both $\mathrm{CD}^{+}{ }^{+} \mathrm{T}$ cells and B cells were required for induction of effective immunity following immunization with the heat killed vaccine, whereas $\mathrm{CD}^{+} \mathrm{T}$ cells appeared to be dispensable. Depletion of IFN- $\gamma$ or TNF- $\alpha$ immediately prior to challenge also reduced vaccine effectiveness, suggesting a role for these cytokines in protective immunity.

\section{Alternative vaccine approaches}

Dendritic cell vectored vaccines have been shown to induce effective immunity against both pathogens and cancer. A DC vaccine prepared using DC pulsed in vitro with heat-killed B. pseudomallei was evaluated for effectiveness in a mouse B. pseudomallei challenge model (Elvin et al., 2006). Mice receiving the DC vaccine were significantly protected against challenge with virulent B. pseudomallei when delivered by the i.p. route.

Outer membrane vesicles (OMVs), which are secreted by bacteria during in vitro culture, have also been evaluated as candidate immunogens for Burkholderia pseudomallei and mallei (Hara et al., 2009; Nieves et al., 2011; Schell et al., 2011). Immunization with B. pseudomallei OMVs by the s.c. route was found recently to produce significant protection against pulmonary challenge with virulent $B$. pseudomallei. Induction of both cellular and humoral responses to vaccination was observed. Interestingly, immunization with OMVs by the intranasal route was not effective in generating protective immunity. OMV immunization also did not provide protection against chronic infection (Nieves et al., 2011).

The bacterial Elongation Factor-Tu $(E F-T u)$, which is also secreted in OMVs is immunogenic (Harding et al., 2007), and was evaluated as a vaccine antigen (Nieves et al., 2010). Immunization by the intranasal route resulted in reduced bacterial burden when mice were subjected to intranasal challenge with $B$. thailandensis (Nieves et al., 2010).

\section{CHALLENGES FACING Burkholderia VACCINE DEVELOPMENT}

While substantial progress has been made in the development of effective vaccines for Burkholderia, significant hurdles still remain. In the case of subunit vaccines, it is not clear whether new and more immunogenic target antigens have yet to be discovered. High throughput screening strategies may facilitate the identification of such antigens. In addition, the development of new polyvalent vaccines may provide more effective and broader coverage against $B$. pseudomallei infection than single subunit vaccines, which is particularly important given the high genetic diversity of different $B$. pseudomallei isolates, even from the same patients.

It will also be important to more fully define the correlates of protective immunity to Burkholderia. For example, given that $\mathrm{CD}^{+}{ }^{+} \mathrm{T}$ cells are important in protective immunity, are certain $\mathrm{CD}^{+}{ }^{+} \mathrm{T}$ cell functional subsets (eg, Th17, Th2, or Th1 cells) more desirable than others in generating strong and long-lasting protective humoral and cellular immune responses? It is also likely that the role of $\mathrm{CD}^{+} \mathrm{T}$ cells may be more important than early studies have suggested, particularly for prevention of the chronic stage of infection.

Given that chronic Burkholderia infection is likely contracted via mucosal routes of exposure to Burkholderia, development of vaccines that generate strong mucosal immune responses and IgA production is an important goal. This will necessitate the use of challenge models that mimic natural route of exposure, including oral and inhalational exposure, as well as cutaneous inoculation. Newer vaccine adjuvants may be particularly effective in development of strong humoral or cellular immune responses, or more balanced responses, depending on what is required for 
protective immunity. The route of immunization is also an important variable, particularly for vaccines designed to provide protection from pulmonary or oral challenge with Burkholderia.

Is there a future for a live attenuated Burkholderia vaccine? At present, these vaccines are the most likely to generate full protective immunity against a broad range of Burkholderia strains, using relatively simple immunization protocols. Whether these vaccines will be adopted will depend on the target population for the intended vaccine and the willingness of local regulatory authorities to approve live attenuated vaccines. Full

\section{REFERENCES}

Allwood, E. M., Devenish, R. J., Prescott, M., Adler, B., and Boyce, J. D. (2011). Strategies for intracellular survival of Burkholderia pseudomallei. Front. Microbiol. 2:170. doi: 10.3389/fmicb.2011.00170

Amemiya, K. (2002). Nonviable Burkholderia mallei induces a mixed Th1- and Th2-like cytokine response in $\mathrm{BALB} / \mathrm{c}$ mice. Infect. Immun. 70, 2319-2325.

Anuntagool, N., and Sirisinha, S. (2002). Antigenic relatedness between Burkholderia pseudomallei and Burkholderia mallei. Microbiol. Immunol. 46, 143-150.

Atkins, T., Prior, R., Mack, K., Russell, P., Nelson, M., Prior, J., et al. (2002a). Characterisation of an acapsular mutant of Burkholderia pseudomallei identified by signature tagged mutagenesis. J. Med. Microbiol. 51, 539-547.

Atkins, T., Prior, R. G., Mack, K., Russell, P., Nelson, M., Oyston, P. C., et al. (2002b). A mutant of Burkholderia pseudomallei, auxotrophic in the branched chain amino acid biosynthetic pathway, is attenuated and protective in a murine model of melioidosis. Infect. Immun. 70, 5290-5294.

Aucoin, D. P., Reed, D. E., Marlenee, N. L., Bowen, R. A., Thorkildson, P., Judy, B. M., et al. (2012). Polysaccharide specific monoclonal antibodies provide passive protection against intranasal challenge with Burkholderia pseudomallei. PLoS ONE 7:e35386. doi: 10.1371/journal.pone.0035386

Bandara, A. B., Deshazer, D., Inzana, T. J., Sriranganathan, N., Schurig, G. G., and Boyle, S. M. (2008). A disruption of ctpA encoding carboxy-terminal protease attenuates Burkholderia mallei and induces partial protection in CD1 mice. Microb. Pathog. 45, 207-216.

Barnes, J. L., and Ketheesan, N. (2005). Route of infection in melioidosis. Emerging Infect. Dis. 11, 638-639.
Barnes, J. L., and Ketheesan, N. (2007). Development of protective immunity in a murine model of melioidosis is influenced by the source of Burkholderia pseudomallei antigens. Immunol. Cell Biol. 85, 551-557.

Barnes, J. L., Williams, N. L., and Ketheesan, N. (2008). Susceptibility to Burkholderia pseudomallei is associated with host immune responses involving tumor necrosis factor receptor-1 (TNFR1) and TNF receptor-2 (TNFR2). FEMS Immunol. Med. Microbiol. 52, 379-388.

Blancou, J. (1994). Early methods for the surveillance and control of glanders in Europe. Rev. Sci. Tech. 13, 545-557.

Bottex, C., Gauthier, Y. P., Hagen, R. M., Finke, E. J., Splettstosser, W. D., Thibault, F. M., et al. (2005). Attempted passive prophylaxis with a monoclonal anti-Burkholderia pseudomallei exopolysaccharide antibody in a murine model of melioidosis. Immunopharmacol. Immunotoxicol. 27, 565-583.

Breitbach, K., Klocke, S., Tschernig, T., Van Rooijen, N., Baumann, U., and Steinmetz, I. (2006). Role of inducible nitric oxide synthase and NADPH oxidase in early control of Burkholderia pseudomallei infection in mice. Infect. Immun. 74, 6300-6309.

Breitbach, K., Kohler, J., and Steinmetz, I. (2008). Induction of protective immunity against Burkholderia pseudomallei using attenuated mutants with defects in the intracellular life cycle. Trans. R. Soc. Trop. Med. Hyg. 102(Suppl. 1), S89-S94.

Breitbach, K., Sun, G. W., Kohler, J., Eske, K., Wongprompitak, P., Tan, G., et al. (2009). Caspase-1 mediates resistance in murine melioidosis. Infect. Immun. 77, 1589-1595.

Breitbach, K., Wongprompitak, P., and Steinmetz, I. (2011). Distinct roles for nitric oxide in resistant C57BL/6 and susceptible $\mathrm{BALB} / \mathrm{c}$ mice to control Burkholderia pseudomallei

demonstration of vaccine safety and efficacy against a variety of different challenge strains and routes can help advance the case for live attenuated Burkholderia vaccines. Finally, while a number of candidate vaccines have demonstrated an ability to protect from acute challenge with Burkholderia, it is not currently possible to provide effective protection against the development of chronic Burkholderia infection. Thus, greater attention to development of effective mucosal Burkholderia vaccines that are capable of generating sterilizing immunity is warranted in the future.

infection. BMC Immunol. 12:20. doi: $10.1186 / 1471-2172-12-20$

Brett, P. J., Mah, D. C., and Woods, D. E. (1994). Isolation and characterization of Pseudomonas pseudomallei flagellin proteins. Infect. Immun. 62, 1914-1919.

Bryan, L. E., Wong, S., Woods, D. E., Dance, D. A., and Chaowagul, W. (1994). Passive protection of diabetic rats with antisera specific for the polysaccharide portion of the lipopolysaccharide isolated from Pseudomonas pseudomallei. Can. J. Infect. Dis. 5, 170-178.

Burtnick, M. N., Brett, P. J., Harding, S. V., Ngugi, S. A., Ribot, W. J., Chantratita, N., et al. (2011). The cluster 1 type VI secretion system is a major virulence determinant in Burkholderia pseudomallei. Infect. Immun. 79, 1512-1525.

Burtnick, M. N., Brett, P. J., Nair, V., Warawa, J. M., Woods, D. E., and Gherardini, F. C. (2008). Burkholderia pseudomallei type III secretion system mutants exhibit delayed vacuolar escape phenotypes in RAW 264.7 murine macrophages. Infect. Immun. 76, 2991-3000.

Ceballos-Olvera, I., Sahoo, M., Miller, M. A., Del Barrio, L., and Re, F. (2011). Inflammasome-dependent pyroptosis and IL-18 protect against Burkholderia pseudomallei lung infection while IL-1beta is deleterious. PLoS Pathog. 7:e1002452. doi: 10.1371/journal.ppat.1002452

Chanchamroen, S., Kewcharoenwong, C., Susaengrat, W., Ato, M., and Lertmemongkolchai, G. (2009). Human polymorphonuclear neutrophil responses to Burkholderia pseudomallei in healthy and diabetic subjects. Infect. Immun. 77, 456-463.

Chaowagul, W., White, N. J., Dance, D. A., Wattanagoon, Y., Naigowit, P., Davis, T. M., et al. (1989). Melioidosis: a major cause of community-acquired septicemia in northeastern Thailand. J. Infect. Dis. 159, 890-899.
Charuchaimontri, C., Suputtamongkol, Y., Nilakul, C., Chaowagul, W., Chetchotisakd, P., Lertpatanasuwun, N., et al. (1999). Antilipopolysaccharide II: an antibody protective against fatal melioidosis. Clin. Infect. Dis. 29, 813-818.

Chen, Y. S., Hsiao, Y. S., Lin, H. H., Liu, Y., and Chen, Y. L. (2006). CpGmodified plasmid DNA encoding flagellin improves immunogenicity and provides protection against Burkholderia pseudomallei infection in BALB/c mice. Infect. Immun. 74, 1699-1705.

Cheng, A. C., and Currie, B. J. (2005). Melioidosis: epidemiology, pathophysiology, and management. Clin. Microbiol. Rev. 18, 383-416.

Chenthamarakshan, V., Vadivelu, J., and Puthucheary, S. D. (2001). Detection of immunoglobulins $\mathrm{M}$ and $G$ using culture filtrate antigen of Burkholderia pseudomallei. Diagn. Microbiol. Infect. Dis. 39, 1-7.

Chua, K. L., Chan, Y. Y., and Gan, Y. H. (2003). Flagella are virulence determinants of Burkholderia pseudomallei. Infect. Immun. 71, 1622-1629.

Cuccui, J., Easton, A., Chu, K. K., Bancroft, G. J., Oyston, P. C., Titball, R. W., et al. (2007). Development of signature-tagged mutagenesis in Burkholderia pseudomallei to identify genes important in survival and pathogenesis. Infect. Immun. 75, 1186-1195.

Currie, B. J., Dance, D. A., and Cheng, A. C. (2008). The global distribution of Burkholderia pseudomallei and melioidosis: an update. Trans. $R$. Soc. Trop. Med. Hyg. 102(Suppl. 1), S1-S4.

Currie, B. J., and Jacups, S. P. (2003). Intensity of rainfall and severity of melioidosis, Australia. Emerging Infect. Dis. 9, 1538-1542.

Dance, D. A. (2002). Melioidosis. Curr. Opin. Infect. Dis. 15, 127-132.

Deshazer, D., Brett, P. J., Carlyon, R., and Woods, D. E. (1997). Mutagenesis of Burkholderia pseudomallei with Tn5-OT182: isolation 
of motility mutants and molecular characterization of the flagellin structural gene. J. Bacteriol. 179, 2116-2125.

Deshazer, D., Brett, P. J., and Woods, D. E. (1998). The type II O-antigenic polysaccharide moiety of Burkholderia pseudomallei lipopolysaccharide is required for serum resistance and virulence. Mol. Microbiol. 30, 1081-1100.

Detmers, F. J., Lanfermeijer, F. C., and Poolman, B. (2001). Peptides and ATP binding cassette peptide transporters. Res. Microbiol. 152, 245-258.

Druar, C., Yu, F., Barnes, J. L., Okinaka, R. T., Chantratita, N., Beg, S., et al. (2008). Evaluating Burkholderia pseudomallei Bip proteins as vaccines and Bip antibodies as detection agents. FEMS Immunol. Med. Microbiol. 52, 78-87.

Dvorak, G. D., and Spickler, A. R. (2008). Glanders. J. Am. Vet. Med. Assoc. 233, 570-577.

Easton, A., Haque, A., Chu, K., Lukaszewski, R., and Bancroft, G. J. (2007). A critical role for neutrophils in resistance to experimental infection with Burkholderia pseudomallei. J. Infect. Dis. 195, 99-107.

Eberl, L. (2006). Quorum sensing in the genus Burkholderia. Int. J. Med. Microbiol. 296, 103-110.

Elvin, S. J., Healey, G. D., Westwood, A., Knight, S. C., Eyles, J. E., and Williamson, E. D. (2006). Protection against heterologous Burkholderia pseudomallei strains by dendritic cell immunization. Infect. Immun. 74, 1706-1711.

Foulongne, V., Walravens, K., Bourg, G., Boschiroli, M. L., Godfroid, J., Ramuz, M., et al. (2001). Aromatic compound-dependent Brucella suis is attenuated in both cultured cells and mouse models. Infect. Immun. 69, 547-550.

Fritz, D. L., Vogel, P., Brown, D. R., and Waag, D. M. (1999). The hamster model of intraperitoneal Burkholderia mallei (glanders). Vet. Pathol. 36, 276-291.

Gilad, J., Harary, I., Dushnitsky, T., Schwartz, D., and Amsalem, Y. (2007). Burkholderia mallei and Burkholderia pseudomallei as bioterrorism agents: national aspects of emergency preparedness. Isr. Med. Assoc. J. 9, 499-503.

Goodyear, A., Bielefeldt-Ohmann, H., Schweizer, H., and Dow, S. (2012a). Persistent gastric colonization with Burkholderia pseudomallei and dissemination from the gastrointestinal tract following mucosal inoculation of mice. PLoS ONE 7:e37324. doi: 10.1371/journal.pone.0037324

Goodyear, A., Troyer, R., BielefeldtOhmann, H., and Dow, S. (2012b). MyD88-dependent recruitment of monocytes and dendritic cells required for protection from pulmonary Burkholderia mallei infection. Infect. Immun. 80, 110-120.

Goodyear, A., Jones, A., Troyer, R., Bielefeldt-Ohmann, H., and Dow, S. (2010). Critical protective role for MCP-1 in pneumonic Burkholderia mallei infection. J. Immunol. 184, 1445-1454.

Goodyear, A., Kellihan, L., BielefeldtOhmann, H., Troyer, R., Propst, K., and Dow, S. (2009). Protection from pneumonic infection with Burkholderia species by inhalational immunotherapy. Infect. Immun. 77, 1579-1588.

Haque, A., Chu, K., Easton, A., Stevens, M. P., Galyov, E. E., Atkins, T., et al. (2006a). A live experimental vaccine against Burkholderia pseudomallei elicits CD4+ T cell-mediated immunity, priming $\mathrm{T}$ cells specific for 2 type III secretion system proteins. J. Infect. Dis. 194, 1241-1248.

Haque, A., Easton, A., Smith, D. O'Garra, A., Van Rooijen, N., Lertmemongkolchai, G., et al. (2006b). Role of $\mathrm{T}$ cells in innate and adaptive immunity against murine Burkholderia pseudomallei infection. J. Infect. Dis. 193, 370-379.

Hara, Y., Mohamed, R., and Nathan, S. (2009). Immunogenic Burkholderia pseudomallei outer membrane proteins as potential candidate vaccine targets. PLoS ONE 4:e6496. doi: 10.1371/journal.pone.0006496

Harding, S. V., Sarkar-Tyson, M., Smither, S. J., Atkins, T. P., Oyston, P. C., Brown, K. A., et al. (2007). The identification of surface proteins of Burkholderia pseudomallei. Vaccine 25, 2664-2672.

Harland, D. N., Chu, K., Haque, A., Nelson, M., Walker, N. J., Sarkar-Tyson, M., et al. (2007). Identification of a LolC homologue in Burkholderia pseudomallei, a novel protective antigen for melioidosis. Infect. Immun. 75, 4173-4180.

Harley, V. S., Dance, D. A., Drasar, B. S., and Tovey, G. (1998). Effects of Burkholderia pseudomallei and other Burkholderia species on eukaryotic cells in tissue culture. Microbios 96, 71-93.

Healey, G. D., Elvin, S. J., Morton, M., and Williamson, E. D. (2005) Humoral and cell-mediated adaptive immune responses are required for protection against Burkholderia pseudomallei challenge and bacterial clearance postinfection. Infect. Immun. 73, 5945-5951.

Henderson, A., Propst, K., Kedl, R., and Dow, S. (2011). Mucosal immunization with liposome-nucleic acid adjuvants generates effective humoral and cellular immunity. Vaccine 29, 5304-5312.

Hii, C. S., Sun, G. W., Goh, J. W., Lu, J., Stevens, M. P., and Gan, Y. H. (2008). Interleukin-8 induction by Burkholderia pseudomallei can occur without Toll-like receptor signaling but requires a functional type III secretion system. J. Infect. Dis. 197, 1537-1547.

Ho, M., Schollaardt, T., Smith, M. D., Perry, M. B., Brett, P. J., Chaowagul, W., et al. (1997) Specificity and functional activity of anti-Burkholderia pseudomalle polysaccharide antibodies. Infect. Immun. 65, 3648-3653.

Hodgson, K. A., Morris, J. L., Feterl, M. L., Govan, B. L., and Ketheesan, N. (2011). Altered macrophage function is associated with severe Burkholderia pseudomallei infection in a murine model of type 2 diabetes. Microbes Infect. 13 1177-1184.

Jones, A. L., Beveridge, T. J., and Woods, D. E. (1996). Intracellular survival of Burkholderia pseudomallei. Infect. Immun. 64, 782-790.

Jones, S. M., Ellis, J. F., Russell, P., Griffin, K. F., and Oyston, P. C. (2002). Passive protection against Burkholderia pseudomallei infection in mice by monoclonal antibodies against capsular polysaccharide, lipopolysaccharide or proteins. J. Med. Microbiol. 51, 1055-1062.

Ko, W. C., Cheung, B. M., Tang, H J., Shih, H. I., Lau, Y. J., Wang, L. R., et al. (2007). Melioidosis outbreak after typhoon, southern Taiwan. Emerging Infect. Dis. 13 896-898.

Koo, G. C., and Gan, Y. H. (2006). The innate interferon gamma response of $\mathrm{BALB} / \mathrm{c}$ and $\mathrm{C} 57 \mathrm{BL} / 6$ mice to in vitro Burkholderia pseudomallei infection. BMC Immunol. 7:19. doi: 10.1186/1471-2172-7-19

Liu, B., Koo, G. C., Yap, E. H., Chua, K. L., and Gan, Y. H. (2002) Model of differential susceptibility to mucosal Burkholderia pseudomallei infection. Infect. Immun. 70, 504-511.

Mack, K., and Titball, R. W. (1996). Transformation of Burkholderia pseudomallei by electroporation. Anal. Biochem. 242, 73-76.

Matthysse, A. G., Yarnall, H. A., and Young, N. (1996). Requirement for genes with homology to $\mathrm{ABC}$ transport systems for attachment and virulence of Agrobacterium tumefaciens. J. Bacteriol. 178, 5302-5308.

Nelson, M., Prior, J. L., Lever, M. S., Jones, H. E., Atkins, T. P., and Titball, R. W. (2004). Evaluation of lipopolysaccharide and capsular polysaccharide as subunit vaccines against experimental melioidosis. J. Med. Microbiol. 53, 1177-1182.

Ngauy, V., Lemeshev, Y., Sadkowski, L., and Crawford, G. (2005). Cutaneous melioidosis in a man who was taken as a prisoner of war by the Japanese during World War, I. I. J. Clin. Microbiol. 43, 970-972.

Ngugi, S. A., Ventura, V. V., Qazi, O., Harding, S. V., Kitto, G. B., Estes, D. M., et al. (2010). Lipopolysaccharide from Burkholderia thailandensis E264 provides protection in a murine model of melioidosis. Vaccine 28, 7551-7555.

Nierman, W. C., Deshazer, D., Kim, H. S., Tettelin, H., Nelson, K. E., Feldblyum, T., et al. (2004). Structural flexibility in the Burkholderia mallei genome. Proc. Natl. Acad. Sci. U.S.A. 101, 14246-14251.

Nieves, W., Asakrah, S., Qazi, O., Brown, K. A., Kurtz, J., Aucoin, D. P., et al. (2011). A naturally derived outer-membrane vesicle vaccine protects against lethal pulmonary Burkholderia pseudomallei infection. Vaccine 29, 8381-8389.

Nieves, W., Heang, J., Asakrah, S., Honer $\mathrm{Zu}$ Bentrup, K., Roy, C. J., and Morici, L. A. (2010). Immunospecific responses to bacterial elongation factor Tu during Burkholderia infection and immunization. PLoS ONE 5:e14361. doi: 10.1371/journal.pone.0014361

Owen, S. J., Batzloff, M., Chehrehasa, F., Meedeniya, A., Casart, Y., Logue, C. A., et al. (2009). Nasal-associated lymphoid tissue and olfactory epithelium as portals of entry for Burkholderia pseudomallei in murine melioidosis. J. Infect. Dis. 199, 1761-1770.

Peacock, S. J. (2006). Melioidosis. Curr. Opin. Infect. Dis. 19, 421-428.

Perry, M. B., Maclean, L. L. Schollaardt, T., Bryan, L. E., and Ho, M. (1995). Structural characterization of the lipopolysaccharide $\mathrm{O}$ antigens of Burkholderia pseudomallei. Infect. Immun. 63, 3348-3352.

Pilatz, S., Breitbach, K., Hein, N., Fehlhaber, B., Schulze, J., Brenneke, B., et al. (2006). Identification of Burkholderia pseudomallei genes required for the intracellular life 
cycle and in vivo virulence. Infect. Immun. 74, 3576-3586.

Propst, K. L., Mima, T., Choi, K. H., Dow, S. W., and Schweizer, H. P. (2010). A Burkholderia pseudomallei deltapurM mutant is avirulent in immunocompetent and immunodeficient animals: candidate strain for exclusion from select-agent lists. Infect. Immun. 78, 3136-3143.

Reckseidler, S. L., Deshazer, D., Sokol, P. A., and Woods, D. E. (2001). Detection of bacterial virulence genes by subtractive hybridization: identification of capsular polysaccharide of Burkholderia pseudomallei as a major virulence determinant. Infect. Immun. 69, 34-44.

Rosenbloom, M., Leikin, J. B., Vogel, S. N., and Chaudry, Z. A. (2002). Biological and chemical agents: a brief synopsis. Am. J. Ther. 9, 5-14.

Rowland, C. A., Lertmemongkolchai, G., Bancroft, A., Haque, A., Lever, M. S., Griffin, K. F., et al. (2006). Critical role of type 1 cytokines in controlling initial infection with Burkholderia mallei. Infect. Immun. 74, 5333-5340.

Rowland, C. A., Lever, M. S., Griffin, K. F., Bancroft, G. J., and Lukaszewski, R. A. (2010). Protective cellular responses to Burkholderia mallei infection. Microbes Infect. 12, 846-853.

Santanirand, P., Harley, V. S., Dance, D. A., Drasar, B. S., and Bancroft, G. J. (1999). Obligatory role of gamma interferon for host survival in a murine model of infection with Burkholderia pseudomallei. Infect. Immun. 67, 3593-3600.

Sarkar-Tyson, M., Smither, S. J., Harding, S. V., Atkins, T. P., and Titball, R. W. (2009). Protective efficacy of heat-inactivated B. thailandensis, B. mallei or B. pseudomallei against experimental melioidosis and glanders. Vaccine 27, 4447-4451.

Sarkar-Tyson, M., Thwaite, J. E., Harding, S. V., Smither, S. J., Oyston, P. C., Atkins, T. P., et al. (2007). Polysaccharides and virulence of Burkholderia pseudomallei. J. Med. Microbiol. 56, 1005-1010.

Schell, M. A., Ulrich, R. L., Ribot, W. J., Brueggemann, E. E., Hines, H. B., Chen, D., et al. (2007). Type VI secretion is a major virulence determinant in Burkholderia mallei. Mol. Microbiol. 64, 1466-1485.

Schell, M. A., Zhao, P., and Wells, L. (2011). Outer membrane proteome of Burkholderia pseudomallei and Burkholderia mallei from diverse growth conditions. J. Proteome Res. 10, 2417-2424.
Shah, P., and Swiatlo, E. (2006). Immunization with polyamine transport protein PotD protects mice against systemic infection with Streptococcus pneumoniae. Infect. Immun. 74, 5888-5892.

Srilunchang, T., Proungvitaya, T., Wongratanacheewin, S., Strugnell, R., and Homchampa, P. (2009). Construction and characterization of an unmarked aroC deletion mutant of Burkholderia pseudomallei strain A2. Southeast Asian J. Trop. Med. Public Health 40, 123-130.

Srinivasan, A., Kraus, C. N., Deshazer, D., Becker, P. M., Dick, J. D., Spacek, L., et al. (2001). Glanders in a military research microbiologist. N. Engl. J. Med. 345, 256-258.

Stevens, J. M., Ulrich, R. L., Taylor, L. A., Wood, M. W., Deshazer, D., Stevens, M. P., et al. (2005a). Actinbinding proteins from Burkholderia mallei and Burkholderia thailandensis can functionally compensate for the actin-based motility defect of a Burkholderia pseudomallei bimA mutant. J. Bacteriol. 187, 7857-7862.

Stevens, M. P., Stevens, J. M., Jeng, R. L., Taylor, L. A., Wood, M. W., Hawes, P., et al. (2005b). Identification of a bacterial factor required for actin-based motility of Burkholderia pseudomallei. Mol. Microbiol. 56, 40-53.

Stevens, M. P., Haque, A., Atkins, T., Hill, J., Wood, M. W., Easton, A., et al. (2004). Attenuated virulence and protective efficacy of a Burkholderia pseudomallei bsa type III secretion mutant in murine models of melioidosis. Microbiology 150, 2669-2676.

Stevens, M. P., Wood, M. W., Taylor, L. A., Monaghan, P., Hawes, P., Jones, P. W., et al. (2002). An Inv/Mxi-Spa-like type III protein secretion system in Burkholderia pseudomallei modulates intracellular behaviour of the pathogen. Mol. Microbiol. 46, 649-659.

Su, Y. C., Wan, K. L., Mohamed, R., and Nathan, S. (2010). Immunization with the recombinant Burkholderia pseudomallei outer membrane protein Omp85 induces protective immunity in mice. Vaccine 28, 5005-5011.

Sun, G. W., Lu, J., Pervaiz, S., Cao, W. P., and Gan, Y. H. (2005). Caspase-1 dependent macrophage death induced by Burkholderia pseudomallei. Cell. Microbiol. 7, 1447-1458.

Suputtamongkol, Y., Kwiatkowski, D., Dance, D. A., Chaowagul, W., and
White, N. J. (1992). Tumor necrosis factor in septicemic melioidosis. J. Infect. Dis. 165, 561-564.

Tanabe, M., Atkins, H. S., Harland, D. N., Elvin, S. J., Stagg, A. J., Mirza, O., et al. (2006). The ABC transporter protein OppA provides protection against experimental Yersinia pestis infection. Infect. Immun. 74, 3687-3691.

Tiyawisutsri, R., Holden, M. T., Tumapa, S., Rengpipat, S., Clarke, S. R., Foster, S. J., et al. (2007). Burkholderia Hep_Hag autotransporter (BuHA) proteins elicit a strong antibody response during experimental glanders but not human melioidosis. BMC Microbiol. 7:19. doi: 10.1186/1471-2180-7-19

Trevino, S. R., Permenter, A. R., England, M. J., Parthasarathy, N., Gibbs, P. H., Waag, D. M., et al. (2006). Monoclonal antibodies passively protect $\mathrm{BALB} / \mathrm{c}$ mice against Burkholderia malle aerosol challenge. Infect. Immun. 74, 1958-1961.

Tuanyok, A., Stone, J. K., Mayo, M. Kaestli, M., Gruendike, J., Georgia, S., et al. (2012). The genetic and molecular basis of $\mathrm{O}$-antigenic diversity in Burkholderia pseudomallei lipopolysaccharide. PLoS Negl. Trop. Dis. 6:e1453. doi: 10.1371/journal.pntd.0001453

Ulett, G. C., Ketheesan, N., and Hirst, R. G. (2000). Proinflammatory cytokine mRNA responses in experimental Burkholderia pseudomallei infection in mice. Acta Trop. 74, 229-234.

Ulrich, R. L., Amemiya, K., Waag, D. M., Roy, C. J., and Deshazer, D. (2005). Aerogenic vaccination with a Burkholderia mallei auxotroph protects against aerosolinitiated glanders in mice. Vaccine 23, 1986-1992.

Ulrich, R. L., Deshazer, D., Hines, H. B. and Jeddeloh, J. A. (2004). Quorum sensing: a transcriptional regulatory system involved in the pathogenicity of Burkholderia mallei. Infect. Immun. 72, 6589-6596.

Utaisincharoen, P., Anuntagool, N., Arjcharoen, S., Limposuwan, K., Chaisuriya, P., and Sirisinha, S. (2004). Induction of iNOS expression and antimicrobial activity by interferon (IFN)-beta is distinct from IFN-gamma in Burkholderia pseudomallei-infected mouse macrophages. Clin. Exp. Immunol. 136, 277-283.

Vasu, C., Vadivelu, J., and Puthucheary, S. D. (2003). The humoral immune response in melioidosis patients during therapy. Infection 31 , 24-30.
Ventura, G. M., Balloy, V., Ramphal, R., Khun, H., Huerre, M., Ryffel, B., et al. (2009). Lack of MyD88 protects the immunodeficient host against fatal lung inflammation triggered by the opportunistic bacteria Burkholderia cenocepacia. J. Immunol. 183, 670-676.

Waag, D. M., England, M. J., and Deshazer, D. (2012). Humoral immune responses in a human case of glanders. Clin. Vaccine Immunol. $19,814-816$

Wajanarogana, S., Sonthayanon, P., Wuthiekanun, V., Panyim, S., Simpson, A. J., and Tungpradabkul, S. (1999). Stable marker on flagellin gene sequences related to arabinose non-assimilating pathogenic Burkholderia pseudomallei. Microbiol. Immunol. 43, 995-1001.

Warawa, J., and Woods, D. E. (2002). Melioidosis vaccines. Expert Rev. Vaccines 1, 477-482.

Warawa, J., and Woods, D. E. (2005). Type III secretion system cluster 3 is required for maximal virulence of Burkholderia pseudomallei in a hamster infection model. FEMS Microbiol. Lett. 242, 101-108.

Warawa, J. M., Long, D., Rosenke, R. Gardner, D., and Gherardini, F. C. (2009). Role for the Burkholderia pseudomallei capsular polysaccharide encoded by the wcb operon in acute disseminated melioidosis. Infect. Immun. 77, 5252-5261.

West, T. E., Chierakul, W., Chantratita, N., Limmathurotsakul, D., Wuthiekanun, V., Emond, M. J., et al. (2012). Toll-like receptor 4 region genetic variants are associated with susceptibility to melioidosis. Genes Immun. 13, 38-46.

West, T. E., Ernst, R. K., JanssonHutson, M. J., and Skerrett, S. J. (2008). Activation of Toll-like receptors by Burkholderia pseudomallei. BMC Immunol. 9:46. doi: 10.1186/1471-2172-9-46

White, N. J. (2003). Melioidosis. Lancet 361, 1715-1722.

Whitehead, N. A., Barnard, A. M., Slater, H., Simpson, N. J., and Salmond, G. P. (2001). Quorum-sensing in Gram-negative bacteria. FEMS Microbiol. Rev. 25, 365-404.

Whitlock, G. C., Deeraksa, A., Qazi, O., Judy, B. M., Taylor, K., Propst, K. L., et al. (2010). Protective response to subunit vaccination against intranasal Burkholderia mallei and B. pseudomallei challenge. Procedia Vaccinol. 2, 73-77. 
Whitlock, G. C., Lukaszewski, R. A., Judy, B. M., Paessler, S., Torres, A. G., and Estes, D. M. (2008). Host immunity in the protective response to vaccination with heatkilled Burkholderia mallei. BMC Immunol. 9:55. doi: 10.1186/14712172-9-55

Whitlock, G. C., Robida, M. D., Judy, B. M., Qazi, O., Brown, K. A., Deeraksa, A., et al. (2011). Protective antigens against glanders identified by expression library immunization. Front. Microbiol. 2:227. doi: 10.3389/ fmicb.2011.00227

Wiersinga, W. J., Dessing, M. C., Kager, P. A., Cheng, A. C., Limmathurotsakul, D., Day, N. P., et al. (2007a). Highthroughput mRNA profiling characterizes the expression of inflammatory molecules in sepsis caused by Burkholderia pseudomallei. Infect. Immun. 75, 3074-3079.

Wiersinga, W. J., Wieland, C. W., Dessing, M. C., Chantratita, N., Cheng, A. C., Limmathurotsakul, D., et al. (2007b). Toll-like receptor 2 impairs host defense in gram-negative sepsis caused by Burkholderia pseudomallei (Melioidosis). PLoS Med. 4:e248. doi: 10.1371/journal.pmed.0040248

Wiersinga, W. J., Wieland, C. W., Van Der Windt, G. J., De Boer, A., Florquin, S., Dondorp, A., et al. $(2007 c)$. Endogenous interleukin18 improves the early antimicrobial host response in severe melioidosis. Infect. Immun. 75, 3739-3746.

Wiersinga, W. J., and Van Der Poll, T. (2009). Burkholderia pseudomallei tropism and the melioidosis road map. J. Infect. Dis. 199, 1720-1722.

Wiersinga, W. J., Wieland, C. W., Roelofs, J. J., and Van Der Poll,
T. (2008). MyD88 dependent signaling contributes to protective host defense against Burkholderia pseudomallei. PLoS ONE 3:e3494. doi: 10.1371/journal.pone.0003494

Yakushi, T., Masuda, K., Narita, S., Matsuyama, S., and Tokuda, H. (2000). A new ABC transporter mediating the detachment of lipid-modified proteins from membranes. Nat. Cell Biol. 2, 212-218.

Zhang, S., Feng, S. H., Li, B., Kim, H. Y., Rodriguez, J., Tsai, S., et al. (2011). In vitro and In vivo studies of monoclonal antibodies with prominent bactericidal activity against Burkholderia pseudomallei and Burkholderia mallei. Clin. Vaccine Immunol. 18 825-834.

Conflict of Interest Statement: The authors declare that the research was conducted in the absence of any commercial or financial relationships that could be construed as a potential conflict of interest.

Received: 28 August 2012; accepted: 20 February 2013; published online: 11 March 2013.

Citation: Silva EB and Dow SW (2013) Development of Burkholderia mallei and pseudomallei vaccines. Front. Cell. Infect. Microbiol. 3:10. doi: 10.3389/ fcimb.2013.00010

Copyright (c) 2013 Silva and Dow. This is an open-access article distributed under the terms of the Creative Commons Attribution License, which permits use, distribution and reproduction in other forums, provided the original authors and source are credited and subject to any copyright notices concerning any third-party graphics etc. 